\title{
Feeding Walnuts and Peanuts Reduced Development of Azoxymethane-Induced Precancerous Lesions
}

\author{
Hadyn Mathew Reid, Rajitha Sunkara, Louis Shackelford, Lloyd T. Walker, \\ Martha Verghese* \\ Nutritional Biochemistry Laboratory, Department of Food and Animal Sciences, Alabama A\&M University, \\ Normal, Alabama, USA \\ Email: *martha.verghese@aamu.edu
}

Received 16 December 2015; accepted 22 May 2016; published 25 May 2016

Copyright (C) 2016 by authors and Scientific Research Publishing Inc.

This work is licensed under the Creative Commons Attribution International License (CC BY). http://creativecommons.org/licenses/by/4.0/

c) (i) Open Access

\begin{abstract}
Walnuts and peanuts contain phytochemicals that exhibit properties that may prevent colon cancer development. The objective was to determine the potential of walnuts and peanuts on Azoxymethane (AOM) induced Aberrant Crypt Foci (ACF) and the activity of detoxification enzymes: Glutathione S-Transferase (GST), Catalase (CAT), and Superoxide Dismutase (SOD) in Fisher 344 male rats. After 1 week acclimatization period, 20 rats were randomly divided into 5 groups. One was fed AIN93G Control (C) diet, 4 groups were fed walnuts $(W)$ and peanuts $(P)$ at $5 \%$ and $10 \%$. At 7 - 8 weeks, rats received $A O M$ injections at $16 \mathrm{mg} / \mathrm{kg}$ body weight (subcutaneously). Rats were killed by $\mathrm{CO}_{2}$ asphyxiation at 17 weeks. Enzyme activities GST, CAT and SOD were determined. ACF incidence in rats fed $W(5 \%$ and $10 \%)$ was 131 and 95 , and in those fed $P(5 \%$ and $10 \%)$ was 110 and 56. Rats fed $W$ and $P$ had a significant $(p<0.05)$ percent reduction $(17.92 \%-65.09 \%)$ in total ACF compared to C (159). Liver GST activity $(\mu \mathrm{mol} / \mathrm{mg})$ in rats fed $\mathrm{W}(5 \%$ and $10 \%)$ was 3.64 and 3.98 , and in those fed $P(5 \%$ and $10 \%)$ was 3.84 and 3.30 , compared to rats fed $C(0.26)$. CAT activity ( $\mu \mathrm{mol} / \mathrm{mg})$ in rats fed $W(5 \%$ and $10 \%)$ was 0.57 and 0.65 and in those fed $P(5 \%$ and $10 \%)$, was 0.76 and 1.26 , compared to rats fed $C(0.14)$. SOD activity $(U / \mathrm{mg})$ in rats fed $W(5 \%$ and $10 \%)$ was 529.38 and 576.57 and in those fed $P(5 \%$ and $10 \%)$, was 293.50 and 466.95 , compared to rats fed C (82.42). Feeding walnuts and peanuts, especially at $10 \%$, significantly $(p<0.05)$ reduced the incidence of AOM induced ACF, likely due to the phytochemicals present in nuts.
\end{abstract}

\section{Keywords}

Aberrant Crypt Foci (ACF), Azoxymethane (AOM), Chemoprevention, Fisher 344 Rats, Nuts

\footnotetext{
"Corresponding author.
}

How to cite this paper: Reid, H.M., Sunkara, R., Shackelford, L., Walker, L.T. and Verghese, M. (2016) Feeding Walnuts and Peanuts Reduced Development of Azoxymethane-Induced Precancerous Lesions. Food and Nutrition Sciences, 7, $440-446$. http://dx.doi.org/10.4236/fns.2016.76045 


\section{Introduction}

Nuts are complex food matrices that have several bioactive compounds. They are very rich in unsaturated fatty acids and many of them contain considerable amounts of monounsaturated fatty acids [1]. They also contain macronutrients, such as protein and fiber; other nutrients, such as potassium, calcium, and magnesium; and phytochemicals, such as phytosterols and phenolic compounds [2]. Walnuts are particularly rich in polyunsaturated fatty acids and total phenols [1] [3]. They come from tall deciduous trees and are in the genus Juglans. Walnuts are a good source of manganese and copper; both of which are essential cofactors in a number of enzymes, such as superoxide dismutase that is important in antioxidant defenses. The omega-3 PUFAs, found in walnuts, also aid in bone health by helping to prevent excessive bone turnover [4]. Peanuts (Arachis hypogaea) are not a true nut and are classified in the legume family (Fabaceae). Produced in several forms, peanuts contain many essential phytonutrients such as niacin, folate, fiber, Vitamin E, manganese and phosphorus. They also contain high levels of unsaturated fat and antioxidants [2].

Phytochemicals are chemical compounds that are naturally found in plants. The phytochemicals in nuts have been connected with several diverse bioactivities, including antioxidant, antiviral, antiproliferative, hypocholesterolemic, and anti-inflammatory actions that may affect the initiation and progression of many pathogenic courses of action [1]. These activities, particularly the antiproliferative and antioxidant properties, make nuts prime candidates as potential anticarcinogenic agents.

The consumption of nuts is inversely associated with the incidence of cardiovascular disease, diabetes, and some forms of cancer. This is evidence enough for several countries to incorporate nuts into dietary guidelines and health claims [5]. Cancer is a multistep process that originates at the genetic level. Colon cancer starts as a small growth of tissue called adenomatous polyps that may or may not be cancerous. If promptly discovered, removing precancerous polyps may prevent colon cancer. However, if they are ignored, polyps may slowly grow and eventually lead to colon cancer over time [6]. Over 95\% of colon cancers are adenocarcinomas; cancers that start in the cells lining the inside of the colon [7]. Colon cancer cells operate the same as many other cancer cells, in that the mechanisms governing their growth have been lost. When the cells that line the colon become malignant, they start growing in a specific local area. The tumor cells may then spread via vascular capillaries, travel through circulation and invade surrounding tissues and organs [8].

Glutathione S-Transferases (GST) are considered one of the most important enzymes in the Phase II detoxification process. GST enzymes aid in the breakdown of several xenobiotics and can catalyze a variety of reactions such as the conjugation of reduced glutathione to toxic electrophilic compounds [9].

Superoxide Dismutase (SOD) enzymes are a class of important antioxidant enzymes that catalyze the dismutation of superoxide into oxygen and hydrogen peroxide, thus protecting the cell from oxidative damage. SOD decreases Reactive Oxygen Species (ROS) generation and lowers oxidative stress [10].

Catalase (CAT) catalyzes the decomposition of hydrogen peroxide, a potent reactive oxygen species, into water and oxygen. It is equally as important and is present in all organisms. Just a single molecule of CAT can decompose millions of hydrogen peroxide molecules every second [11].

Walnuts and peanuts have been known to have several beneficial health protectants; from their high doses of the "good" fat, monounsaturated fat, to many minerals and other bioactive compounds. The medicinal benefits of these nuts are constantly being discovered. They have been known to aid in the prevention of heart disease [2], reduce risk of diabetes [12], and reduce the rate of inflammation [1]. There are several beneficial health properties of walnuts and peanuts due to the phytochemicals, as well as important dietary fat and fiber. However, some more studies show that the important nutrients found in nuts are consumed inadequately in the average American diet [1].

The aim of this study was to determine the chemopreventive potential of walnuts and peanuts (5\% and $10 \%)$ on AOM induced Aberrant Crypt Foci (ACF) and to determine their effect on selected detoxification and antioxidant enzymes.

\section{Materials and Methods}

Chemicals and Dietary Ingredients: All chemicals except AOM were obtained from Sigma Chemical Company (St. Louis, MO). Dietary ingredients were obtained from MP Biomedicals (Costa Mesa, CA). All protocols involving rats were approved by the Institutional Animal Care and Use Committee of Alabama A\&M University, 2010. 
Animals and Housing: Fisher 344 male rats were obtained from Harlan, IN and were housed in stainless steel cages with the temperature and relative humidity maintained at $21^{\circ} \mathrm{C}$ and $50 \%$ respectively. Light and dark cycles were maintained at 12 hours each. Rats had free access to their food and water. American Institute of Nutrition Growth (AIN-93G) diet (control) was initially fed to all the rats for a 1 week acclimatization period. Afterwards, they were divided into 5 groups which included 1 control and 4 treatment groups. Treatment diets included walnuts and peanuts at 5\% and 10\% levels and were prepared as needed. Body weights of the rats were recorded on a biweekly basis and daily feed intakes were recorded.

Carcinogen Injection: At 7 and 8 weeks of age, rats were given 2 subcutaneous (s/c) injections of AOM (Midwestern Research Institute, NCI Chemical Repository Kansas City, MO) at 16 mg/kg body weight in saline to induce ACF.

Sample Collection: Rats were killed by $\mathrm{CO}_{2}$ asphyxiation at 17 weeks of age. The colon, cecum, and liver from each rat were removed and prepared for analysis. The colons were flushed with Phosphate buffer solution (0.1 M, pH 7.2). They were then split longitudinally and set upon a coded strip of filter paper in $10 \%$ buffered formalin. Liver samples were collected and frozen using liquid nitrogen, then stored at $-80^{\circ} \mathrm{C}$ for enzyme activity determination.

Enumeration of ACF: The colons from each rat were cut into proximal and distal sections and then segmented into $2 \mathrm{~cm}$ pieces. Methylene blue $(0.2 \%)$ was used to stain the segments for approximately 5 minutes. They were then examined under a light microscope under low magnification. ACF and the amount of crypts per focus were counted and recorded [13].

Cecal Content Analysis: The cecum of each rat was flushed with potassium phosphate buffer (0.1 M, pH 7.2) and blotted on filter paper to measure cecal weight. The contents of each cecum were removed and the $\mathrm{pH}$ was determined using a $\mathrm{pH}$ meter. Contents were then stored at $-80^{\circ} \mathrm{C}$ for further analysis.

Glutathione S-Transferase (GST) Analysis: One gram of liver was homogenized in $10 \mathrm{ml}$ of potassium phosphate buffer $(0.1 \mathrm{M}, \mathrm{pH} 7.0)$ at $4^{\circ} \mathrm{C}$. Hepatic GST was measured by using commercial kit (Cayman chemical company, MI) by following manufacturer's instructions. The absorbance was measured spectrometrically (BioTek Synergy HT microplate) at $340 \mathrm{~nm}$ [14].

Catalase (CAT) Activity: Catalase activity in liver was performed according to the procedure set by Aebi [15]. All catalase activity was determined against a formaldehyde standard at an absorbance of 540 nm using a (BioTek Synergy HT) microplate reader and was expressed as $\mu \mathrm{M}$ of $\mathrm{H}_{2} \mathrm{O}_{2}$ reduced per minute per ml of protein.

Superoxide Dismutase (SOD) Activity: Using the assay method by Fridovich [16], $1 \mathrm{~g}$ of liver sample was diluted in $9 \mathrm{ml}$ of distilled water. Two $\mathrm{ml}$ of this mixture was added to $2.5 \mathrm{ml}$ of $0.05 \mathrm{M}$ carbonate buffer (pH 10.2) to equilibrate in the spectrometer and the reaction started by the addition of $0.3 \mathrm{ml}$ of freshly prepared $0.3 \mathrm{mM}$ adrenaline to the mixture. This was mixed by in inversion. The cuvette contained $2.5 \mathrm{ml}$ buffer, $0.3 \mathrm{ml}$ of adrenaline (substrate) and $0.2 \mathrm{ml}$ of water. The change in absorbance at $480 \mathrm{~nm}$ was monitored every 30 seconds for 150 seconds.

Statistical Analysis: Results were presented as means \pm SEM using SAS system version 9.1. ANOVA was used to determine significant differences among the treatment groups. Significance was determined at $p \leq 0.05$. The means were separated using Tukey’s Studentized Range Test.

\section{Results}

Weight Gain and Feed Intake: Weight gain and feed intake are shown in Table 1. Rats fed 5\% peanuts had the highest weight gain among all groups; however, rats fed the control had the lowest weight gain. Rats fed $10 \%$ peanuts had the lowest feed intake compared to the other groups, whereas the highest feed intake was seen in rats fed $5 \%$ walnuts.

Cecal Weight and Cecal pH: Cecal weight and cecal pH are shown in Table 2. Rats fed control had significantly $(p<0.05)$ lower cecal weight compared to the treatment groups, whereas rats fed peanuts at $10 \%$ had the highest cecal weight among all groups. The highest cecal $\mathrm{pH}$ was seen in rats fed control and the lowest was seen in rats fed $5 \%$ peanuts.

Aberrant Crypt Foci: Aberrant Crypt Foci are shown in Table 2 and Table 3. ACF found in the proximal colon was significantly ( $p<0.05$ ) lower compared to those found in the distal colon. The highest number of ACF was seen in rats fed control. Rats fed control had a significantly $(p<0.05)$ higher number of ACF comp to those fed the treatment except in rats fed 5\% walnuts. Among treatment groups, rats fed walnuts at 5\% had 
Table 1. Weight gain, average feed intake and Feed Efficiency Ratio (FER) in AOM-induced Fisher 344 Male Rats.

\begin{tabular}{cccc}
\hline Groups & Weight gain $(\mathrm{g} / 13 \mathrm{wk})$ & Feed Intake (g/day) & Feed Efficiency Ratio (FER) \\
\hline Control & $201.10 \pm 5.20^{\mathrm{c}}$ & $17.98^{\mathrm{a}}$ & 11.18 \\
$5 \%$ Walnuts & $218.43 \pm 5.47^{\mathrm{b}}$ & $18.23^{\mathrm{a}}$ & 11.98 \\
$10 \%$ Walnuts & $215.63 \pm 8.09^{\mathrm{b}}$ & $17.83^{\mathrm{a}}$ & 12.09 \\
$5 \%$ Peanuts & $239.25 \pm 8.05^{\mathrm{a}}$ & $16.01^{\mathrm{b}}$ & 14.95 \\
$10 \%$ Peanuts & $218.25 \pm 7.62^{\mathrm{b}}$ & $15.79^{\mathrm{c}}$ & 13.82 \\
\hline
\end{tabular}

Values are expressed as means \pm SEM. ${ }^{\text {abc }}$ Means with different superscripts are significantly $(p<0.05)$ different using Tukey’s Studentized range test.

Table 2. Cecal weight and pH in AOM-induced Fisher 344 Male Rats.

\begin{tabular}{ccc}
\hline Groups & Cecal weight $(\mathrm{g})$ & Cecal pH \\
\hline Control & $0.80 \pm 0.01^{\mathrm{c}}$ & $7.98 \pm 0.02$ \\
$5 \%$ Walnuts & $1.05 \pm 0.09^{\mathrm{b}}$ & $7.75 \pm 0.11$ \\
$10 \%$ Walnuts & $1.18 \pm 0.18^{\mathrm{b}}$ & $7.74 \pm 0.12$ \\
$5 \%$ Peanuts & $1.13 \pm 0.17^{\mathrm{b}}$ & $7.61 \pm 0.09$ \\
$10 \%$ Peanuts & $1.30 \pm 0.07^{\mathrm{a}}$ & $7.66 \pm 0.04$ \\
\hline
\end{tabular}

Values are expressed as means \pm SEM. ${ }^{\text {abc }}$ Means with different superscripts are significantly $(p<0.05)$ different using Tukey’s Studentized range test.

Table 3. Aberrant crypt foci enumeration in rats fed walnuts and peanuts.

\begin{tabular}{cccccc}
\hline Location & Control & Walnuts 5\% & Walnuts 10\% & Peanuts 5\% & Peanuts $10 \%$ \\
\hline Proximal & $31.68 \pm 2.42^{\text {aj }}$ & $29.50 \pm 3.44^{\text {aj }}$ & $12.75 \pm 4.20^{\text {cj }}$ & $17.75 \pm 2.37^{\text {bj }}$ & $10.25 \pm 3.50^{\text {cj }}$ \\
Distal & $127.52 \pm 6.82^{\text {ai }}$ & $101.00 \pm 7.17^{\text {bi }}$ & $82.50 \pm 4.92^{\mathrm{di}}$ & $92.50 \pm 7.29^{\mathrm{ci}}$ & $45.25 \pm 7.70^{\mathrm{ei}}$ \\
Total & $159.00 \pm 8.26^{\text {ah }}$ & $130.50 \pm 7.65^{\text {bh }}$ & $95.25 \pm 7.87^{\text {dh }}$ & $110.25 \pm 8.60^{\text {ch }}$ & $55.5 \pm 7.75^{\text {eh }}$ \\
\hline
\end{tabular}

Values are expressed as means \pm SEM. ${ }^{\text {abcde }}$ Means with different superscripts are significantly $(p<0.05)$ different using Tukey’s Studentized range test (columns). ${ }^{\text {hij }}$ 


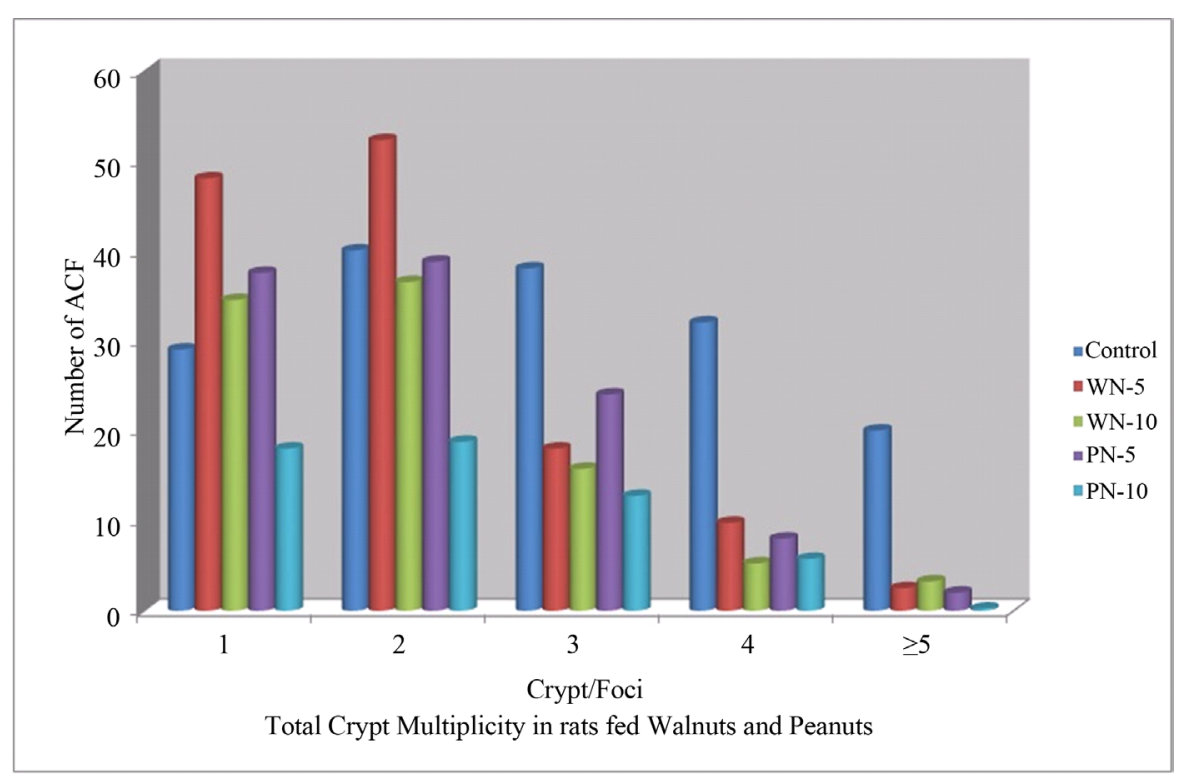

Figure 1. Effect of nuts on crypt multiplicity of rats induced by AOM. WN-5 = 5\% Walnut, WN-10 $=10 \%$ Walnut, PN-5 = 5\% Peanut, PN-10 = 10\% Peanut.

Table 4. Glutathione S-Transferase (GST), Catalase (CAT), and Superoxide Dismutase (SOD) activity in Fisher 344 Male Rats.

\begin{tabular}{|c|c|c|c|}
\hline Treatments & GST activity ( $\mu \mathrm{mol} / \mathrm{mg})$ & CAT activity ( $\mu \mathrm{mol} / \mathrm{mg})$ & SOD activity (U/mg) \\
\hline Control & $0.26 \pm 0.10^{\mathrm{d}}$ & $0.14 \pm 0.02^{\mathrm{c}}$ & $82.42 \pm 3.01^{\mathrm{e}}$ \\
\hline 5\% Walnuts & $3.64 \pm 0.10^{\mathrm{b}}$ & $0.57 \pm 0.06^{\mathrm{b}}$ & $529.38 \pm 6.84^{\mathrm{b}}$ \\
\hline $10 \%$ Walnuts & $3.98 \pm 0.35^{\mathrm{a}}$ & $0.65 \pm 0.09^{\mathrm{b}}$ & $576.57 \pm 10.42^{\mathrm{a}}$ \\
\hline $5 \%$ Peanuts & $3.84 \pm 0.15^{\mathrm{a}}$ & $0.76 \pm 0.06^{\mathrm{b}}$ & $293.50 \pm 5.06^{\mathrm{d}}$ \\
\hline $10 \%$ Peanuts & $3.30 \pm 0.44^{c}$ & $1.26 \pm 0.16^{\mathrm{a}}$ & $466.95 \pm 8.50^{c}$ \\
\hline
\end{tabular}

Values are expressed as means \pm SEM. ${ }^{\text {abcde }}$ Means with different superscripts are significantly $(p<0.05)$ different using Tukey’s Studentized range test.

Rats fed the control diet had significantly $(p<0.05)$ lower SOD activity $(82.42 \pm 3.01)$ compared to those fed diets containing nuts. In fact, SOD activity (U/mg) in rats fed the treatment diets was 3 - 6 fold higher compared to those fed control. The groups fed (5\% and 10\%) walnuts had significantly $(p<0.05)$ higher SOD activity $(\mathrm{U} / \mathrm{mg})(529.38 \pm 6.84$ and $576.57 \pm 10.42)$ compared to the rats fed $(5 \%$ and $10 \%)$ peanuts $(293.5 \pm 5.06$ and $466.95 \pm 8.5)$. The groups fed walnuts and peanuts at the higher $(10 \%)$ level had significantly $(p<0.05)$ higher SOD activity (U/mg) compared to their counterparts fed nuts at the lower (5\%) level (Table 4). SOD activity ranged from a low of 293.5 in rats fed 5\% peanuts to a high of 576.57 in rats fed (10\%) walnuts.

\section{Discussion}

The objective of the study was to determine the effects of feeding walnuts and peanuts on AOM induced aberrant crypt foci in Fisher 344 rats. Research involving the chemopreventive potential of peanuts and walnuts is limited. Aside from a major study in Taiwan [17], as well as a few other experiments with walnuts, the research conducted using nuts on colon cancer is scarce. Walnuts and peanuts contain a vast amount of phytochemicals that are beneficial to healthy cell growth and maintaining proper immune functions. It is important to note that the phytochemical compounds found in these two nuts may work in synergy.

Observations made in this study showed a decrease in the number of ACF in rats fed walnuts and peanuts compared to those fed the control diet. Rats fed the control diet had a significantly higher number of ACF, indicating that feeding walnuts and peanuts at selected levels (5\% and $10 \%)$ reduced the incidence of ACF in the rat model when compared to rats fed a control diet. Rats fed the $5 \%$ peanut diet showed over a $60 \%$ reduction in 
ACF development in both the proximal and distal colons compared to rats fed the control. Much of this may be attributed to the phytochemical make up of these nuts and the anti-proliferative effects they impart. This effect was also seen in crypt multiplicity as well as total number of crypts which is a reliable indicator as it takes into account the number of ACF and crypt multiplicity. ACF are well known precursors to tumor incidence. Rats fed the control diet had a higher number of larger crypts $(\geq 3)$ compared to rats fed walnuts and peanuts. However, smaller crypts $(<3)$ were seen with more frequency in many of the groups fed nuts compared to those fed the control diet. A single aberrant crypt expands by branching or by multiplying and may exhibit a variety of dysplasia as they develop [18]. A higher number of smaller crypts were seen in nut-fed groups which may be due to the anti-proliferative effects of walnuts and peanuts ultimately reducing crypt size. Larger crypts have a greater likelihood of developing into tumors overtime, however small crypts $(<4)$ may dissolve and disappear due to various mechanisms such as apoptosis and others [19]. These results suggest that the selected levels of nuts not only reduced the number of ACF but also reduced the size of the crypts. Research [20] has shown that ACF containing 4 or more crypts have a direct relationship with carcinogenic frequency. Therefore, these results suggest that ACF with 4 or more crypts have a greater propensity to progress into tumors and may be an important factor to predict increased tumor incidence.

The results from this research also indicated that the consumption of walnuts and peanuts had an effect on the activity of selected hepatic enzymes; GST, CAT, and SOD. Glutathione S-transferases (GST) are a family of enzymes that have many functions including catalyzing the conjugation of reduced glutathione, which contributes to the phase II detoxification of xenobiotics to facilitate their dissolution in the aqueous cellular and extracellular media found in the body [21]. In this study, the highest GST activity was seen in the rats fed $10 \%$ walnut and 5\% peanut diets. This suggests that these diets may have provided greater protection against electrophilic compounds compared to rats fed the other diets and also contributed to the excretion of potential toxic compounds from the body. GST often works in conjunction with glutathione in order to conjugate xenobiotic substrates [14]. The results from SOD demonstrated no significance among the 5\% and $10 \%$ walnut and 5\% and $10 \%$ peanut treatment groups.

CAT activity ( $\mu \mathrm{mol} / \mathrm{mg}$ ) ranged from a low of 0.57 to a high of 1.26 in rats fed walnuts and peanuts. The results indicate that rats fed diets containing selected levels of walnuts and peanuts had higher CAT activity compared to those fed the control diet. In the body, CAT is considered one the most important antioxidative enzymes due to its ability to produce water and oxygen through the decomposition of hydrogen peroxide $\left(\mathrm{H}_{2} \mathrm{O}_{2}\right)$. Since hydrogen peroxide is a known oxidizing by-product that can cause cellular and tissue damage, CAT can help convert $\mathrm{H}_{2} \mathrm{O}_{2}$ into harmless substances providing an advantage and may result in chemoprevention [11]. Because of the higher CAT activity in rats fed walnuts and peanuts, we can suggest that the phytochemicals present in the nuts aided in the ability to stimulate CAT/antioxidative activity and; therefore, prevent $\mathrm{H}_{2} \mathrm{O}_{2}$ accumulation and associated cell damage.

SOD activity (U/mg) in rats fed walnuts and peanuts ranged from a low 293.50 to a high of 576.57. The rats fed diets containing nuts had significantly higher SOD activity compared to those fed the control diet. Rats fed walnuts (5\% and 10\%) had higher SOD activity compared to those fed peanuts ( $5 \%$ and $10 \%$ ). This may indicate that the phytochemicals in walnuts play a larger role enhancing SOD activity to help dismutate superoxides compared to those found in peanuts. In the body, SOD operates with CAT synergistically to help breakdown superoxides into harmless substances. It initiates the first step in that breakdown by catalyzing the dismutation of superoxide into oxygen and $\mathrm{H}_{2} \mathrm{O}$ [22].

\section{Conclusion}

This study showed the potential of walnuts and peanuts as chemopreventive agents in reducing aberrant crypt foci induced by AOM in rats. There is supported the knowledge that modified, specifically peanuts and walnuts, may reduce colon cancer risk. An end point tumor model study is strongly recommended and would provide further conclusive evidence; leading the way to human clinical trials and enforcing the dogma that regular or increased consumption of nuts such as walnuts and peanuts may have chemopreventive abilities in the human body.

\section{Acknowledgements}

This study was supported by The Agricultural Experimental Research Station, Alabama A and M University, Normal, Alabama, 35762. 


\section{References}

[1] King, J.C., Blumberg, J., Ingwersen, L., Jenab, M. and Tucker, K.L. (2007) Tree Nuts and Peanuts as Components of a Healthy Diet. The Journal of Nutrition, 138, 1736S-1740S.

[2] Kris-Etherton, P., Hu, F.B., Ros, E. and Sabaté, J. (2008) The Role of Tree Nuts and Peanuts in the Prevention of Coronary Heart Disease: Multiple Potential Mechanisms. The Journal of Nutrition, 138, 1746S-1751S.

[3] Pan, A., Sun, Q., Manson, J.E., Willett, W.C. and Hu, F.B. (2013) Walnut Consumption Is Associated with Lower Risk of Type 2 Diabetes in Women. The Journal of Nutrition, 143, 512-518. http://dx.doi.org/10.3945/jn.112.172171

[4] Griel, A.E., Kris-Etherton, P.M., Hilpert, K.F., Zhao, G., West, S.G. and Corwin, R.L. (2007) An Increase in Dietary n-3 Fatty Acids Decreases a Marker of Bone Resorption in Humans. Nutrition Journal, 6, 2. http://dx.doi.org/10.1186/1475-2891-6-2

[5] Chen, C.Y.O. and Blumberg, J.B. (2008) Phytochemical Composition of Nuts. Asia Pacific Journal of Clinical Nutrition, 17, 329-332.

[6] American Cancer Society (2012) What Are the Key Statistics about Colorectal Cancer? http://www.cancer.org/Cancer/ColonandRectumCancer/DetailedGuide/colorectal-cancer-key-statistics

[7] American Cancer Society (2010) What Are the Key Statistics for Colorectal Cancer? http://www.cancer.org/Cancer/ColonandRectumCancer/DetailedGuide/colorectal-cancer-key-statistics

[8] Weidner, N., Semple, J.P., Welch, W.R. and Folkman, J. (1991) Tumor Angiogenesis and Metastasis-Correlation in Invasive Breast Carcinoma. The New England Journal of Medicine, 324, 1-8. http://dx.doi.org/10.1056/NEJM199101033240101

[9] Leaver, M.J. and George, S.G. (1998) A Piscine Glutathione S-Transferase Which Efficiently Conjugates the EndProducts of Lipid Peroxidation. Marine Environmental Research, 46, 71-74. http://dx.doi.org/10.1016/S0141-1136(97)00071-8

[10] Segui, J., Gironella, M., Sans, M., Granell, S., Gil, F., Gimeno, M., Coronel, P., Pique, J.M. and Panes, J. (2004) Superoxide Dismutase Ameliorates TNBS-Induced Colitis by Reducing Oxidative Stress, Adhesion Molecule Expression, and Leukocyte Recruitment into the Inflamed Intestine. Journal of Leukocyte Biology, 76, 537-544. http://dx.doi.org/10.1189/jlb.0304196

[11] Goodsell, D.S. (2004) Catalase. Molecule of the Month. RCSB Protein Data Bank. http://www.rcsb.org/pdb/static.do?p=education_discussion/molecule_of_the_month/pdb57_1.html

[12] Allen, L.H. (2008) Priority Areas for Research on the Intake, Composition, and Health Effects of Tree Nuts and Peanuts. The Journal of Nutrition, 138, 1753S-1765S.

[13] Bird, R.P. (1987) Observation and Quantification of Aberrant Crypts in the Murine Colon Treated with a Colon Carcinogen: Preliminary Findings. Cancer Letters, 37, 147-151. http://dx.doi.org/10.1016/0304-3835(87)90157-1

[14] Habig, W.H., Pabst, M.J. and Jakoby, W.B. (1974) Glutathione S-Transferases. The First Enzymatic Step in Mercapturic Acid Formation. The Journal of Biological Chemistry, 249, 7130-7139.

[15] Aebi, H. (1984) Catalase in Vitro. Methods in Enzymology, 105, 121-126. http://dx.doi.org/10.1016/S0076-6879(84)05016-3

[16] Fridovich, I. (1989) Superoxide Dismutases: An Adaptation to a Paramagnetic Gas. The Journal of Biological Chemistry, 264, 7761-7764.

[17] Yeh, C.C., You, S.L., Chen, C.J. and Sung, F.C. (2006) Peanut Consumption and Reduced Risk of Colorectal Cancer in Women: A Prospective Study in Taiwan. World Journal of Gastroenterology, 12, 222-227. http://dx.doi.org/10.3748/wjg.v12.i2.222

[18] Bird, R.P. and Good, C.K. (2000) The Significance of Aberrant Crypt Foci in Understanding the Pathogenesis of Colon Cancer. Toxicology Letters, 112-113, 395-402. http://dx.doi.org/10.1016/S0378-4274(99)00261-1

[19] Makin, G. and Hickman, J.A. (2000) Apoptosis and Cancer Chemotherapy. Cell and Tissue Research, 301, $143-152$. http://dx.doi.org/10.1007/s004419900160

[20] Uchida, K., Kado, S., Onoue, M. and Tohyama, K. (1997) Relationship between the Nature of Mucus and Crypt Multiplicity in Aberrant Crypt Foci in the Rat Colon. Cancer Science, 88, 807-814.

[21] Boyland, E. and Chasseaud, L.F. (1969) The Role of Glutathione and Glutathione S-Transferases in Mercapturic Acid Biosynthesis. Advances in Enzymology and Related Areas of Molecular Biology, 32, 173-219. http://dx.doi.org/10.1002/9780470122778.ch5

[22] Sun, Y., Oberley, L.W. and Li, Y. (1988) A Simple Method for Clinical Assay of Superoxide Dismutase. Clinical Chemistry, 34, 497-500. 